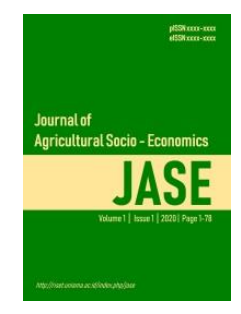

Journal of Agricultural Socio-Economics (JASE)

eISSN 2745-6897| pISSN 2745-6889

Volum 1 Issue 2 (2020) Page 67-75

DOI: http://dx.doi.org/10.33474/jase.v1i2.9095

Submit: 17-08-2020 | Accepted: 28-09-2020 | Publish: 14-10-2020

\title{
Efisiensi produksi sawi pakcoy (Brasica rapa L.) di Desa Sumberejo Kota Batu
}

\author{
Lukas Irwantus Dangkung ${ }^{1}$, Agnes Quartina Pudjiastuti ${ }^{1}{ }^{*}$, Ninin Khoirunnisa $^{1}$ \\ ${ }^{1}$ Program Studi Agribisnis, Fakultas Pertanian, Universitas Tribhuwana Tunggadewi Malang, Indonesia \\ *E-mail: agnespudjiastuti@yahoo.com
}

\begin{abstract}
Pakcoy mustard (Brasica rapa L.) has a relatively high economic value in terms of low farming costs, so it has the potential to continue to be developed because the community widely consumes it both in fresh and processed form. The development of the population and industrial users of pakcoy mustard as a raw material causes this commodity's demand to continue to increase. This study aimed to analyze the production efficiency of pakcoy mustard in the village of Sumberejo. This village is one of the pakcoy mustard production centers in Batu City. The data was collected through interviews with 45 pakcoy farmers selected from 350 pakcoy farmers in the research location. The data that has been collected were analyzed with the Cobb-Douglas production function, then the allocative efficiency was calculated. The results showed that the use of seeds, TSP, and NPK fertilizers in pakcoy mustard production in the village of Sumberejo, Batu City was not allocatively efficient.
\end{abstract}

Keywords: efficiency, production, pakcoy, allocatif

Abstrak. Sawi pakcoy (Brasica rapa L.) memiliki nilai ekonomi cukup tinggi, pada hal biaya usahatani cukup rendah sehingga berpotensi untuk terus dikembangkan karena banyak dikonsumsi oleh masyarakat baik dalam bentuk segar maupun olahan. Perkembangan penduduk dan industri pengguna sawi pakcoy sebagai bahan baku menyebabkan permintaan komoditas ini terus meningkat. Tujuan penelitian ini adalah menganalisis efisiensi produksi sawi pakcoy di Desa Sumberejo. Desa ini merupakan salah satu sentra produksi sawi pakcoy di Kota Batu. Pengumpulan data dilakukan melalui wawancara dengan 45 petani pakcoy yang dipilih secara acak sederhana dari 350 petani sawi pakcoy yang ada di lokasi penelitian. Data yang telah dikumpulkan dianalisis dengan fungsi produksi Cobb-Douglas, untuk selanjutnya dihitung efisensi alokatifnya. Hasil penelitian menunjukkan bahwa penggunaan benih, pupuk TSP dan NPK pada produksi sawi pakcoy di Desa Sumberejo Kota Batu tidak efisien secara alokatif.

Kata Kunci: efisiensi, produksi, pakcoy, alokatif

\section{PENDAHULUAN}

Sawi pakcoy (Brasica Rapa L.) tercatat di BPS ke dalam golongan tanaman sehabis panen langsung dicabut yang produksinya 1.503.446 ton pada tahun 2018 dengan produktivitas 6,59 ton per hektar. Meskipun tidak termasuk ke dalam klasifikasi tanaman semusim yang diekspor, sawi memiliki pertumbuhan produksi yang lebih tinggi dibandingkan kentang, bayam dan kangkung, tetapi masih lebih rendah dibandingkan wortel (BPS, 2019). Pemenuhan kebutuhan domestik terhadap sawi dapat berkontribusi pada neraca perdagangan (Pudjiastuti et al., 2013) (Pudjiastuti, 2014) (Pudjiastuti \& Kembauw, 2018). Agar kebutuhan domestik terpenuhi, produksi dan produktivitas tanaman sayuran daun ini, harus selalu ditingkatkan. Sementara, produktivitas yang tinggi terkait erat dengan konsep efisiensi yang menjadi salah satu pilar yang harus diwujudkan dalam memuliakan petani untuk mencapai swasembada (Sulaiman et al., 2018).

Efisiensi produksi dapat dianalogikan sebagai penggunaan input minimum untuk menghasilkan output tertentu, atau penggunaan input tertentu untuk menghasilkan output maksimum. Oleh karenanya, penting untuk diketahui terlebih dahulu, bagaimana hubungan fungsional antara input 
dan output agar dapat menganalisis efisiensi. Menurut Soekartawi (2006), fungsi produksi Cobb Douglas dapat digunakan sebagai penduga untuk mengukur efisiensi untuk komoditas pertanian, termasuk sawi dengan berbagai jenisnya.

Penelitian tentang efisiensi usahatani sawi telah dilakukan tetapi belum banyak, sehingga efisiensi usahatani sayuran daun lainnya akan dikemukakan di sini sebagai bahan kajian. Sawi ditanam petani Desa Bannae karena umur panennya yang singkat, dan dapat tumbuh pada musim kemarau sehingga intensitas penanamannya tinggi, tetapi tingkat pendapatannya tergolong rendah (Hane \& Kune, 2018). Sebagian besar (65\%) unsur biaya produksi sawi adalah sarana produksi (bibit, pupuk, pestisida). Produktivitas sawi di tercatat $1.500,35 \mathrm{~kg}$ per ha (Suratman, 2018), $4.150 \mathrm{~kg}$ per MT (F. N. Lestari et al., 2019), $10 \mathrm{ku} / 1750 \mathrm{~m}$ persegi (Suherman, 2019). Produktivitas di beberapa daerah lokasi penelitian tersebut tergolong rendah. Namun demikian, usahatani sawi masih dikatakan layak untuk dilakukan karena R/C >1 (A. Damayanti, 2016)(Opat \& Hutapea, 2017)(Normansyah et al., 2014) (Azzura et al., 2017).

Di sisi lain, usahatani sawi ditemukan masih belum efisien secara alokatif di mana fungsi produksi Cobb Douglas digunakan sebagai penduga dengan faktor produksi luas lahan, benih, pupuk, pestisida, tenaga kerja (Rakhmawati et al., 2011)(Lama \& Kune, 2016) (Silitonga et al., 2017)(Halim \& Suherman, 2019)(Hukom et al., 2019)(O. F. Lestari et al., 2020)(Hermawan et al., 2020). Ini menjadi sinyal bagi petani sawi untuk merubah kombinasi faktor produksi atau memilih faktor produksi yang biayanya lebih murah, sehingga masih diperlukan melakukan kajian tentang efisiensi usahatani sawi pakcoy di daerah lainnya agar memberikan informasi yang lebih lengkap.

Masih terbatasnya kajian tentang efisiensi usahatani sawi pakcoy, maka dilakukan kajian literatur berbasis penelitian tentang pendapatan usahatani dan efisiensi dengan menggunakan fungsi produksi Cobb Douglas, tetapi komoditasnya bukan tanaman sawi. Hasil kajian tentang bayam (Kamisi, 2013)(Mufriantie \& Feriady, 2014), kangkung air (Lamusa, 2005), wortel (Wahyuningsih et al., 2020), kubis (Masithoh et al., 2013), tomat (Sita \& Hadi, 2016)(Amane et al., 2019), buncis (Kalauw et al., 2015), menemukan bahwa tanaman sayuran ini pada umumnya menguntungkan, tetapi produksinya tidak dianalisis sehingga tidak bisa diketahui apakah lebih rendah atau lebih tinggi dibandingkan yang seharusnya. Tingkat pendapatan petani bervariasi menurut jenis sayuran dan penggunaan factor produksinya belum/tidak efisien.

Pertumbuhan dan produksi sawi juga sangat tergantung pada media dan pupuk yang digunakan (N. S. Damayanti et al., 2019), konservasi (Sholeh, 2014). Oleh karena itu, efisiensi alokatif produksi sawi di Desa Sumberejo perlu dikaji untuk lebih memperkaya pengetahuan tentang penggunaan faktor produksi komoditas ini yang lebih spesifik (terinci) dan dapat menjadi pedoman bagi petani. Oleh kaena itu tujuan penelitian ini adalah menganalisis pengaruh luas lahan, benih, pupuk kandang, pupuk NPK, pupuk TSP, pupuk urea, tenaga kerja dan pestisida terhadap produksi sawi pakcoy (Brasica Rapa L.) dan efisiensi alokatif penggunaan faktor-faktor produksi tersebut di Desa Sumberejo.

\section{METODE}

\subsection{Metode Penentuan Sampel}

Populasi dari penelitian ini adalah petani sawi pakcoy di Desa Sumberejo, Kecamatan Batu, Kota Batu. Populasi petani sawi ini berjumlah 350 orang yang tersebar di 12 kelompok tani. Sampel ditentukan secara acak sederhana dengan pertimbangan bahwa luas lahan yang diusahakan petani sawi tidak bervariasi. Jumlah sampel ditentukan dengan menggunakan rumus Slovin:

di mana, $\mathrm{n}$ : Jumlah Sampel

$$
\mathrm{n}=\frac{\mathrm{N}}{1+\mathrm{Ne}^{2}}
$$

$\mathrm{N}$ : Jumlah Populasi

e : Tingkat ketelitian yang diinginkan (15\%).

Berdasarkan rumus tersebut, maka banyaknya sampel adalah:

$$
\mathrm{n}=\frac{350}{1+350(0,15)^{2}}=\frac{350}{1+7,875}=\frac{350}{8,875}=40 \text { petani sawi pakcoy }
$$

Jadi jumlah sampel minimum dalam penelitian ini adalah 40 petani sawi pakcoy. 


\subsection{Metode Analisis Data}

Data primer dikumpulkan melalui wawancara dengan para petani yang telah terpilih sebagai sampel dengan menggunakan kuesioner sebagai instrumen penelitian dan observasi ke lahan petani. Wawancara dilakukan dengan 45 petani sawi pakcoy dengan tujuan jika terdapat data yang kurang lengkap sehingga tidak bisa digunakan dalam analisis, jumlah sampel minimum sebesar 40 petani tetap terpenuhi. Data sekunder dikumpulkan dengan menggunakan metode dokumentasi berupa artikel hasil penelitian, dokumen lembaga Badan Pusat Statistik (BPS) dan lembaga lainnya.

Data yang dikumpulkan melalui wawancara diedit di lapang agar informasi yang diperoleh sesuai dan lengkap. Seluruh kuesioner telah terisi lengkap dan tidak terdapat data yang kosong sehingga jumlah data setiap variabel adalah 45 . Selanjutnya data ditabulasi dan dikompilasi untuk dianalisis.

Untuk mencapai tujuan pertama yaitu analisis faktor-faktor yang mempengaruhi produksi sawi, digunakan fungsi produksi Cobb-Douglas yang secara matematis dapat ditulis:

di mana:

$$
\mathrm{Y}=a_{0} \mathrm{X} 1^{a 1} \mathrm{X} 2^{a 2} \mathrm{X} 3^{a 3} \times 4^{a 4} \times 5^{a 5} \times 6^{a 6} \times 7^{a 7} \times 8^{a 8}
$$

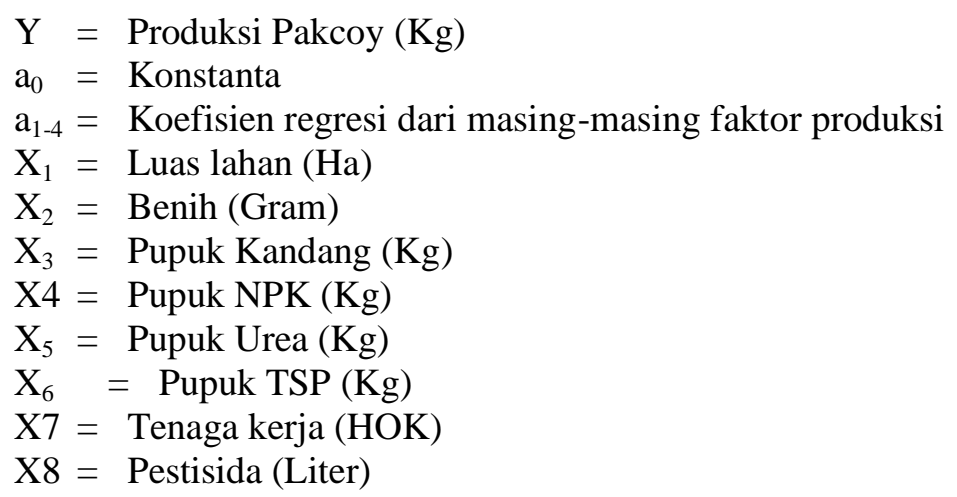

Model tersebut ditransformasikan menjadi linear berganda yang berbentuk logaritma,yang secara matematis dituliskan sebagai:

$\ln Y=\ln a_{0}+a_{1} \ln X_{1}+a_{2} \ln X_{2}+a_{3} \ln X_{3}+a_{4} \ln X_{4}+a_{5} \ln X_{5}+a_{6} \ln x_{6}+a_{7} \ln x_{7}+a_{8} \ln x_{8}$

Transformasi fungsi produksi tersebut dimaksudkan agar data bisa diolah dengan software SPSS karena pengolah data ini tidak memiliki fungsi pangkat. Langkah selanjutnya adalah melakukan uji asumsi klasik (yaitu uji tentang normalitas data, multikolinieritas dan heteroskedastisitas), cek kesesuaian model berdasarkan koefisien determinasi, analisis regresi linear berganda, dan kemudian mentransformasi kembali fungsi regresi linier berganda ke fungsi produksi Cobb Douglas. Berdasarkan hasil analisis regresi, akan dapat diketahui faktor-faktor produksi yang berpengaruh signifikan pada produksi sawi pakcoy.

Untuk mencapai tujuan kedua yaitu menganalisis efisiensi produksi sawi pakcoy, dibuat perhitungan efisiensi alokatif. Efisiensi alokatif atau harga merupakan suatu tolok ukur tingkat keberhasilan petani dalam usahataninya dengan mendapatkan keuntungan maksimum. Efisiensi ini tercapai jika (Anindita dkk., 2011):

$$
\begin{aligned}
& N^{N P M_{X}}=P_{X} \\
& \frac{N M_{X}}{P_{X}}=1 \\
& \frac{\text { b. Y. } P_{Y}}{X}=P_{X} \\
& \frac{\text { b.Y.P. }}{X . P_{X}}=1
\end{aligned}
$$


Di mana:

$$
\begin{array}{ll}
\mathrm{NPM}_{\mathrm{X}} & =\text { nilai produk marginal } \mathrm{x} \\
\mathrm{P}_{\mathrm{x}} & =\text { harga faktor produksi } \mathrm{x} \\
\mathrm{b} & =\text { elastisitas } \\
\mathrm{Y} & =\text { produksi } \\
\mathrm{Y} & =\text { harga produksi } \mathrm{Y} \\
\mathrm{X} & =\text { jumlah faktor produksi } \mathrm{X}
\end{array}
$$

Kriteria efisiensi alokatif (harga) adalah:

$$
\begin{aligned}
& \text { Jika } \frac{\mathrm{NPM}_{\mathrm{X}}}{\mathrm{P}_{\mathrm{X}}}>1 \text {, berarti penggunaan input produksi (x) belum efisien. Justifikasinya adalah input } \mathrm{X} \\
& \text { perlu ditambahkan penggunaannya. } \\
& \frac{\mathrm{NPM}_{\mathrm{X}}}{\mathrm{P}_{\mathrm{X}}}=1 \text {, berarti penggunaan input produksi (x) telah efisien. } \\
& \frac{\mathrm{NPM}_{\mathrm{X}}}{\mathrm{P}_{\mathrm{X}}}<1 \text {, berarti penggunaan input produksi (x) tidak efisien. Justifikasinya adalah input } \mathrm{X} \\
& \text { harus dikurangi penggunaannya. }
\end{aligned}
$$

\section{HASIL DAN PEMBAHASAN}

\subsection{Profil Petani Sawi Pakcoy Desa Sumberejo}

Desa Sumberejo memiliki luas lahan sawah 89 ha dengan 84 ha berpengairan teknis dan sisanya berpengairan setengah teknis. Seluruh lahan sawah ini tidak ditanami padi, melainkan jenis tanaman lainnya terutama sayuran sepanjang tahun 2018. Selain lahan sawah, wilayah ini juga memiliki tegal/kebuh seluas 117.90 ha. Ada 22 jenis sayuran yang diusahakan di mana sawi menghasilkan luas panen terbesar kedua (BPS, 2019). Usahatani sawi pakcoy dibudidayakan oleh petani di Desa Sumberejo selama lebih dari 40 tahun.

Petani sawi pakcoy di Desa Sumberejo memiliki karakteristik yang akan menentukan keberhasilan dalam berusahatani meliputi umur, jenis kelamin, pendidikan, pengalaman bertani, beban tanggungan, luas lahan, status lahan (Tabel 1). Menurut umurnya, sebagian besar $(93,3 \%)$ petani berada pada usia produktif. Hal ini relevan dengan pemilihan komoditi yang bersifat komersial, memerlukan pemeliharaan yang lebih besar karena beresiko, dan mudah rusak seperti umumnya ciri komoditi pertanian.

Umumnya $(86,67 \%)$ petani adalah laki-laki, di mana $60 \%$ berpendidikan SMP ke bawah, $80 \%$ memiliki pengalaman bertani 8-35 tahun, seluruhnya menguasai lahan < 0,6 hektar dengan status sewa (64\%), $75 \%$ memiliki tanggungan 2-3 orang. Ini menunjukkan bahwa usahatani sawi pakcoy menarik bagi petani karena dianggap menguntungkan sehingga petani mau berusahatani sawi dengan menyewa lahan yang relatif sempit $(<0,6$ hektar $)$.

Tabel 1. Distribusi Petani Sawi Pakcoy Berdasarkan Karakteristiknya

\begin{tabular}{clcc}
\hline No & Umur (Tahun) & Jumlah (Jiwa) & $\begin{array}{c}\text { Persentase } \\
(\%)\end{array}$ \\
\hline 1 & $18-65$ & 42 & 93,3 \\
& $>65$ & 3 & 6,67 \\
\cline { 2 - 4 } & Jumlah & 45 & 100 \\
\hline 2 & Jenis Kelamin & & \\
\hline \multirow{2}{*}{} & Laki-Laki & 39 & 86,67 \\
& Perempuan & 6 & 18,33 \\
\hline & Jumlah & 45 & 100 \\
\hline 3 & Pendidikan & & \\
\hline & SD/Sederajat & 15 & 33,33 \\
& SMP/Sederajat & 12 & 26,67 \\
& SMA/Sederajat & 17 & 37,78 \\
& Diploma & 1 & 2,22 \\
\hline & Jumlah & 45 & 100 \\
\hline 4 & Pengalaman Bertani (Tahun) & & \\
\hline
\end{tabular}




\begin{tabular}{llcc}
\hline & $8-35$ & 36 & 80 \\
& $36-49$, & 9 & 20 \\
\hline & Jumlah & 45 & 100 \\
\hline 5 & Luas Lahan (ha) & & \\
\hline & $\leq 0,20$ & 20 & 44,44 \\
& $0,21-0,40$ & 19 & 42,22 \\
& $0,41-0,60$ & 6 & 13,33 \\
\hline & Jumlah & 45 & 100 \\
\hline 6 & Jumlah Tanggungan (Jiwa) & & \\
\hline & 1 & 4 & 8,89 \\
& 2 & 10 & 22,22 \\
& 3 & 24 & 53,33 \\
& 4 & 7 & 15,56 \\
\hline & Jumlah & 45 & 100 \\
\hline 7 & Status Lahan & & \\
\hline & Milik Sendiri & 16 & 35,56 \\
& Sewa & 29 & 64,44 \\
\cline { 2 - 4 } & Jumlah & 45 & 100 \\
\hline
\end{tabular}

Sumber: Data primer diolah, 2020

\subsection{Faktor-Faktor yang Mempengaruhi Produksi Sawi Pakcoy di Desa Sumberejo}

Sawi pakcoy di Desa Sumberejo dibudidayakan petani di lahan milik sendiri dan lahan sewa dengan luasan dan karakteristik petani lainnya yang bervariasi (Tabel 1). Pengaruh faktor produksi dalam penelitian ini yang meliputi luas lahan, benih, pupuk kandang, pupuk TSP, pupuk NPK, pupuk urea, tenaga kerja dan pestisida terhadap produksi sawi pakcoy dapat dilihat di Tabel 2. Hasil analisis ini telah melalui uji asumsi klasik (normalitas data, uji multikolinieritas dan heteroskedastisitas). Data dinyatakan menyebar normal berdasarkan kriteria Kolmogorov-Smirnov $Z$ sebesar 0,562 > 0,05.

Uji asumsi multikolinieritas menggunakan besaran tolerance dan variance inflation factor (VIF) dengan alpha/tolerance $=10 \%$ dan VIF $=10$ disajikan di Tabel 2. VIF hitung dari seluruh factor produksi < 10 dan semua tolerance factor produksi sawi pakcoy di atas 10\%, sehingga dapat dinyatakan di antara faktor produksi tidak terjadi multikolinieritas.

Tabel 2. Hasil Uji Multikolinieritas dan Heteroskesdatisitas

\begin{tabular}{llccc}
\hline \multirow{2}{*}{ No } & \multirow{2}{*}{ Variabel } & \multicolumn{2}{c}{ Collinearity Statistics } & Uji Glesjer \\
\cline { 3 - 5 } & & Tolerance & VIF & Sig. \\
\hline 1 & Luas Lahan $\left(\mathrm{X}_{1}\right)$ & .152 & 6.599 & .638 \\
2 & Benih $\left(\mathrm{X}_{2}\right)$ & .116 & 8.632 & .319 \\
3 & Pupuk Kandang $\left(\mathrm{X}_{3}\right)$ & .464 & 2.157 & .429 \\
4 & Pupuk TSP $\left(\mathrm{X}_{4}\right)$ & .297 & 3.363 & .775 \\
5 & Pupuk NPK $\left(\mathrm{X}_{5}\right)$ & .219 & 4.574 & .353 \\
6 & Pupuk Urea $\left(\mathrm{X}_{6}\right)$ & .315 & 3.174 & .181 \\
7 & Tenaga Kerja $\left(\mathrm{X}_{7}\right)$ & .432 & 2.313 & .125 \\
8 & Pestisida $\left(\mathrm{X}_{8}\right)$ & .669 & 1.494 & .061 \\
\hline
\end{tabular}

Sumber: Data primer diolah, 2020

Heteroskedastisitas dalam hal ini adalah kondisi di mana terjadi ketidaksamaan varian dari error untuk semua pengamatan setiap faktor produksi dalam model regresi. Hasil uji glesjer yang dicantumkan pada Tabel 2 menunjukkan bahwa semua faktor produksi sawi pakcoy memenuhi asumsi homoskedastisitas atau tidak terjadi heteroskedastisitas karena setiap input memiliki sig. $>0,05$.

Oleh karena tidak terjadi pelanggaran terhadap asumsi klasik dalam analisis fungsi regresi, maka dilanjutkan dengan analisis pengaruh faktor-faktor produksi terhadap produksi sawi pakcoy. Hasil analisis ini disajikan di Tabel 3.

Tabel 3. Pengaruh Faktor-Faktor Produksi Terhadap Produksi Sawi Pakcoy 


\begin{tabular}{|c|c|c|c|c|c|c|}
\hline \multirow[t]{2}{*}{ Variabel } & \multicolumn{3}{|c|}{$\begin{array}{c}\text { Unstandardized } \\
\text { Coefficients }\end{array}$} & \multirow{2}{*}{$\begin{array}{c}\text { Standardized } \\
\text { Coefficients }\end{array}$} & \multirow[t]{2}{*}{$\mathrm{t}$} & \multirow[t]{2}{*}{ Sig. } \\
\hline & $\mathrm{B}$ & \multicolumn{2}{|c|}{ Std. Error } & & & \\
\hline Constanta & & .624 & 1.390 & & .449 & .656 \\
\hline Luas Lahan $\left(\mathrm{X}_{1}\right)$ & & $1.014 * *$ & .193 & .937 & 5.265 & .000 \\
\hline $\operatorname{Benih}\left(\mathrm{X}_{2}\right)$ & & -.195 & .283 & -.140 & -.690 & .495 \\
\hline Pupuk Kandang $\left(\mathrm{X}_{3}\right)$ & & .021 & .101 & .021 & .208 & .836 \\
\hline Pupuk TSP $\left(\mathrm{X}_{4}\right)$ & & .048 & .162 & .038 & .297 & .768 \\
\hline Pupuk NPK $\left(\mathrm{X}_{5}\right)$ & & .184 & .198 & .138 & .928 & .359 \\
\hline Pupuk Urea $\left(X_{6}\right)$ & & .111 & .173 & .079 & .640 & .526 \\
\hline Tenaga Kerja $\left(X_{7}\right)$ & & $-.413 *$ & .210 & -.207 & -1.968 & .057 \\
\hline Pestisida $\left(\mathrm{X}_{8}\right)$ & & .251 & .167 & .127 & 1.501 & .142 \\
\hline \multicolumn{7}{|l|}{$\overline{\mathrm{R}^{2}}=.827$} \\
\hline \multicolumn{7}{|l|}{ F hit. $=21.540$} \\
\hline Sig. $F=0,000$ & & & & & & \\
\hline
\end{tabular}

Sumber: Data primer diolah, 2020

Hasil analisis di Tabel 3 menunjukkan bahwa secara simultan, luas lahan, benih, pupuk kandang, pupuk TSP, pupuk NPK, pupuk urea, tenaga kerja dan pestisida berpengaruh signifikan terhadap produksi sawi pakcoy. Koefisien determinasi menunjukkan bahwa 82,7\% variasi produksi pakcoy ditentukan oleh faktor produksi yang diamati. Namun secara parsial, luas lahan berpengaruh sangat signifikan dengan arah hubungan yang positif dan tenaga kerja berpengaruh signifikan dengan arah hubungan yang negatif terhadap produksi sawi pakcoy. Sementara factor produksi lainnya tidak berpengaruh signifikan. Seperti yang telah disebutkan dalam profil petani, sebagian besar lahan untuk budidaya sawi di Desa Sumberejo merupakan lahan sewa. Oleh karena itu, petani berupaya semaksimal mungkin agar lahan yang dikelolanya bisa menghasilkan produksi yang maksimum sesuai faktor produksi yang digunakan agar memperoleh keuntungan. Hasil penelitian ini sesuai dengan hasil penelitian Rakhmawati dkk., 2011; Silitonga dkk, 2017; Halim dan Suherman, 2019.

Benih, pupuk TSP dan tenaga kerja mempunyai pengaruh yang tidak signifikan dengan arah hubungan yang negatif, sementara pupuk kandang, pupuk NPK, pupuk urea dan pestisida juga mempunyai pengaruh yang tidak signifikan tetapi dengan arah hubungan yang positif.

Berdasarkan hasil analisis regresi, fungsi produksi sawi pakcoy secara matematis dapat dinyatakan sebagai berikut.

$$
\mathrm{Y}=0,699 \mathrm{X}_{1}{ }^{0,970} \mathrm{X}_{2}{ }^{-0,171} \mathrm{X}_{3}{ }^{0,006} \mathrm{X}_{4}{ }^{-0,163} \mathrm{X}_{5}{ }^{0,359} \mathrm{X}_{6}{ }^{0,087} \mathrm{X}_{7}{ }^{-0,368} \mathrm{X}_{8}{ }^{0,364}
$$

Fungsi produksi sawi ini menunjukkan bahwa produksi sawi bersifat increasing return to scale, karena jumlah koefisien faktor produksi adalah 1,084. Implikasinya, petani dapat meningkatkan produksi sawinya 1,084 kali lipat jika meningkatkan faktor-faktor produksi 1 kali lipat

\subsection{Efisiensi Harga Faktor-Faktor Produksi Sawi Pakcoy Di Desa Sumberejo}

Efisiensi penggunaan faktor produksi dapat menjadi sinyal bagi produsen (dalam hal ini petani sawi pakcoy) untuk mengetahui apakah berbagai faktor produksi yang digunakan dalam proses produksi telah digunakan dengan proporsi yang sesuai. Informasi ini juga penting bagi penyuluh dan pemerintah atau pihak lain yang memiliki kepedulian terhadap kesejahteraan para petani. Efisiensi harga (alokatif) produksi sawi disajikan di Tabel 4. 
Tabel 4. Efisiensi Harga (Alokatif) dalam Produksi Sawi Pakcoy

\begin{tabular}{|c|c|c|c|c|c|c|c|c|}
\hline Variabel & $\mathbf{b}$ & $\mathbf{Y}$ & Py & $\mathbf{X}$ & $\mathbf{P x}$ & b.Y.Py & X.Px & b.Y.Py/X.Px \\
\hline Luas Lahan & 1,014 & 4466,22 & 1.500 & 1462,22 & 3.000 & 6793121 & 4386660 & 1,54859 \\
\hline Benih & 0,195 & 4466,22 & 1.500 & 10 & 10.000 & -1306369 & 100000 & $-13,064$ \\
\hline Pupuk Kandang & 0,021 & 4466,22 & 1.500 & 533,78 & 1.000 & 140686 & 533780 & 0,26357 \\
\hline Pupuk TSP & 0,048 & 4466,22 & 1.500 & 161,04 & 2.000 & 321568 & 322080 & 0,99841 \\
\hline Pupuk NPK & 0,184 & 4466,22 & 1.500 & 125,67 & 3.000 & 1232677 & 377010 & 3,26961 \\
\hline Pupuk Urea & 0,111 & 4466,22 & 1.500 & 162,22 & 2.000 & 743626 & 324440 & 2,29203 \\
\hline Tenaga Kerja & 0,413 & 4466,22 & 1.500 & 331,73 & 80.000 & -2766823 & 26538400 & $-0,1043$ \\
\hline Pestisida & 0,251 & 4466,22 & 1.500 & 249,07 & 54 & 1681532 & 13449,78 & 125,023 \\
\hline
\end{tabular}

Tabel 4 menunjukkan bahwa untuk faktor produksi pupuk kandang, TSP dan tenaga kerja mempunyai nilai efisiensi lebih kecil dari satu, artinya penggunaan faktor produksi tersebut tidak efisien. Oleh karena itu, untuk memperoleh tingkat keuntungan maksimum faktor produksi tersebut harus dikurangi. Luas lahan, benih, pupuk NPK, pupuk urea dan pestisida mempunyai nilai efisien lebih dari satu, artinya penggunaan faktor produksi tersebut dari aspek biaya belum efisien. Implikasinya, penggunaan faktor produksi ini perlu ditambah agar biaya produksi optimal. Dengan kata lain, petani harus mengalokasikan penggunaan faktor produksi sawi pakcoy agar biaya produksi lebih rendah. Hasil analisis ini sama dengan hasil penelitian Silitonga dkk, 2017; Halim dan Suherman, 2019; Hukom dkk, 2019; Lestari dkk., 2020; dan Hermawan dkk., 2020.

\section{KESIMPULAN}

Luas lahan mempunyai pengaruh sangat signifikan dengan arah hubungan yang positif terhadap produksi sawi pakcoy di Desa Sumberejo, tenaga kerja berpengaruh signifikan dengan arah yang negatif, sementara faktor produksi lainnya tidak berpengaruh signifikan. Penggunaan seluruh faktor produksi dalam usahatani sawi pakcoy belum termasuk ke dalam kategori efisien secara alokatif. Faktor produksi pupuk kandang, TSP dan tenaga kerja efisiensi alokatifnya <1, sehingga faktor produksi tersebut harus dikurangi. Luas lahan, benih, pupuk NPK, pupuk urea dan pestisida efisiensi alokatifnya $>1$, sehingga dapat ditingkatkan pengunaannya.

Petani sawi pakcoy di Desa Sumberejo perlu melakukan realokasi faktor-faktor produksi yang digunakan selama ini. Pertimbangan ini dapat difokuskan pada luas lahan dan tenaga kerja karena input ini yang memiliki pengaruh signifikan terhadap produksi sawi pakcoy. Kajian selanjutnya disarankan untuk menambahkan faktor produksi lainnya atau lebih mendalami penggunaan input yang pengaruhnya tidak signifikan.

\section{DAFTAR PUSTAKA}

Amane, G. S., Bahari, B., \& Geo, L. O. (2019). Analisis Efisiensi Alokasi Penggunaan Faktor Produksi Pada Usahatani Tomat Di Kecamatan Kapontori Kabupaten Buton. Jurnal Sosio Agribisnis, 4(1), 26-33. https://doi.org/10.33772/jsa.v4i1.7420

Azzura, D., Marsudi, E., \& Usman, M. (2017). Analisis Pendapatan Usahatani Sayur-Sayuran dan Faktor-Faktor yang Mempengaruhinya di kecamatan darussalam kabupaten Aceh Besar. Jurnal Ilmiah Mahasiswa Pertanian Unsyiah, 2(3), 92-105.

BPS. (2019). Statistik Tanaman Sayuran dan Buah-Buahan Semusim Indonesia 2018. In S. S. Hortikultura (Ed.). BPS RI. https://www.bps.go.id/publication/2019/10/07/9c5dede09c805bc38302ea1c/statistik-tanamansayuran-dan-buah---buahan-semusim-indonesia-2018.html

Damayanti, A. (2016). Analisis usahatani sawi di Dusun Taman Arum Kecamatan Loa Kulu Kabupaten Kutai Kartanegara. Magrobis Journal, 16(1), 23-32.

Damayanti, N. S., Widjajanto, D. W., \& Sutarno, S. (2019). Pertumbuhan dan produksi tanaman sawi Pakcoy (Brassica rapa 1.) akibat dibudidayakan pada berbagai media tanam dan dosis pupuk 
organik. Journal Agro Complex, 3(3), 142-150. https://doi.org/10.14710/joac.3.3.142-150

Halim, A., \& Suherman. (2019). Analisis Pendapatan Petani Sayur Sawi di Kecamatan Paal merah Kota Jambi. Jurnal Development, 7(1), 8-14.

Hane, A., \& Kune, S. J. (2018). Analisis Pendapatan Usahatani Sawi di Kawasan Ekonomi Masyarakat Desa Bannae Kecamatan Insana Barat. Agrimor, 3(2), 27-29. https://doi.org/10.32938/ag.v3i2.242

Hermawan, W., Noor, T. I., \& Setia, H. B. (2020). Faktor - Faktor Yang Mempengaruhi Produksi Sawi Hijau ( Suatu Kasus di Desa Sukamaju Kecamatan Cimaung Kabupaten Bandung). Agroinfo Galuh, 7(2), 399-410.

Hukom, J., Kakisina, L.O., \& Sari, R. M. (2019). Analisis produktivitas Petani Sayuran Daun di Desa Passo Kecamatan Baguala Kota Ambon. AGRILAN, 7(3), 227-240.

Kalauw, S. H. S., Timisela, N. R., \& Tuhumury, M. T. F. (2015). Analisis Faktor-Faktor yang Mempengaruhi Produksi Sayuran Buncis (Phaseolus Vulgaris L.) di Dusun Telaga Kodok Kabupaten Maluku Tengah. Agrilan, 3(2), 140-156.

Kamisi, H. La. (2013). Analisis usahatani bayam (Studi kasus di Kelurahan Sasa Kecamatan Ternate Selatan Kota Ternate). Agrikan: Jurnal Ilmiah Agribisnis Dan Perikanan, 6(1), 58. https://doi.org/10.29239/j.agrikan.6.1.58-63

Lama, M., \& Kune, S. J. (2016). Faktor-Faktor yang Mempengaruhi Produksi Usaha Tani Sayur Sawi di Kelurahan Bensone Kecamatan Kota Kefamenanu Kabupaten Timor Tengah Utara. Agrimor, 1(02), 27-29. https://doi.org/10.32938/ag.v1i02.102

Lamusa, A. (2005). Faktor-faktor yang Mempengaruhi Produksi Kangkung Air di Desa Tulo Kecamatan Dolo Kabupaten Donggala Propinsi Sulawesi Tengah. J. Agroland, 12(4), 512-517.

Lestari, F. N., Rianse, S. I., \& Fyka, S. A. (2019). Analisis Perbedaan Pendapatan Usahatani Sawi Semi Organik dan Non Organik di Desa Aunupe Kecamatan Wolasi. Jurnal Ilmiah Agribisnis (Jurnal Agribisnis Dan Ilmu Sosial Ekonomi Pertanian), 4(5), 111-115.

Lestari, O. F., Hasyim, A. I., \& Situmorang, S. (2020). Efisiensi Produksi Usahatani Sayuran (Cabai, Sawi dan Kubis) di Kota pagar Alam Provinsi Sumatera Selatan. JIIA, 8(2), 326-333.

Masithoh, S., Nahraeni, W., \& Prahari, B. (2013). Analisis Efisiensi Penggunaan Faktor-Faktor Produksi Usaha Tani Kubis ( Brassica Oleracea ) Di Kertasari , Bandung, Jawa Barat. Jurnal Pertanian, 4(2), 100-108.

Mufriantie, F., \& Feriady, A. (2014). Analisis Faktor Produksi Dan Efisiensi Alokatif Usahatani Bayam (Amarathus Sp) Di Kota Bengkulu. Agrisep, 15(1), 31-37. https://doi.org/10.24815/agrisep.v15i1.2090

Normansyah, D., Rochaeni, S., \& Humaerah, A. D. (2014). Analisis Pendapatan Usahatani Sayuran Di Kelompok Tani Jaya, Desa Ciaruteun Ilir, Kecamatan Cibungbulang, Kabupaten Bogor. Agribusiness Journal, 8(1), 29-44. https://doi.org/10.15408/aj.v8i1.5127

Opat, E., \& Hutapea, A. N. (2017). Analisis Pendapatan Usahatani Sawi Manis di Kelurahan Oelami, Kecamatan Bikomi Selatan, Kabupaten Timor Tengah Utara. Agrimor, 2(03), 33-35. https://doi.org/10.32938/ag.v2i03.306

Pudjiastuti, A. Q. (2014). Perubahan Neraca Perdagangan Indonesia Sebagai Akibat Penghapusan Tarif Impor Gula. Agriekonomika, 3(2), 106-116.

Pudjiastuti, A. Q., Anindita, R., Nuhfil, H., \& Kaluge, D. (2013). CHANGES EFFECT OF SUGAR IMPORT TARIFF IN INDONESIA. Russian Journal of Agricultural and Socio-Economic Sciences, 3(15), 31-38. https://doi.org/10.18334/np3499

Pudjiastuti, A. Q., \& Kembauw, E. (2018). Sugar Price Policy and Indonesia's Trade Balance. Journal of Advanced Research in Law and Economics, 8(8). https://doi.org/10.14505/jarle.v8.8(30).26

Rakhmawati, K. P., Hasrati, E., \& Sumastuti, E. (2011). Analisis Efisiensi Usahatani Sawi Caisim (Brassica juncea L.) Studi Kasus di Kelompok Tani Agribisnis "Aspakusa Makmur" Teras Kabupaten Boyolali. AGROMEDIA, 29(2), 1-18.

Sholeh, M. S. (2014). Pengaruh Tingkat Penerapan Konservasi terhadap Pendapatan Usahatani Sawi (Brassica juncea L.) di Kecamatan Bumiaji Kota Batu. AGROSAINS, 01(01), 1-11. https://doi.org/10.1038/132817a0

Silitonga, A. S., Damayanti, Y., \& Nainggolan, S. (2017). Analisis Efisiensi Ekonomi Penggunaan Faktor Produksi Pada Beberapa Jenis Usahatani Sayuran Di Kecamatan Sungai Gelam Kabupaten Muaro Jambi. Jurnal Ilmiah Sosio-Ekonomika Bisnis, 20(1), 2. 
https://doi.org/10.22437/jiseb.v20i1.5034

Sita, B. R., \& Hadi, S. (2016). Produktivitas dan Faktor-Faktor yang Berpengaruh Terhadap Produksi Usahatani Tomat (Solanum lycopersicum Mill) di Kabupaten Jember. JSEP, 9(3), 67-78. https://doi.org/10.31967/relasi.v14i2.265

Suherman. (2019). Analisis Rasio Pendapatan Petani Sayuran Sawi Dengan Petani Padi Di Kecamatan Sukorambi Kabupaten Jember. Relasi: Jurnal Ekonomi, 15(1), 175-195. https://doi.org/10.31967/relasi.v15i1.307

Sulaiman, A. A., Las, I., Subagyono, K., Alihamsyah, T., \& Hermanto. (2018). Membangun Lumbung Pangan di Wilayah perbatasan: Sinergitas merintis Ekspor Pangan di Wilayah Perbatasan NKRI (A. Suryana, Hermanto, \& R. Hendayama (eds.)). IAARD PRESS.

Suratman, Y. Y. A. (2018). Analisis Pendapatan Usahatani Sawi (Brassica juncea L.) di Kelurahan Landasan Ulin Utara Kecamatan Liang Anggang Kota Banjarbaru. ZIRAA'AH, 43(2), 133-140. https://doi.org/10.1017/CBO9781107415324.004

Wahyuningsih, T., Pudjiastuti, A. Q., \& Sumarno. (2020). Production Factors Efficiency Of Potato Farming In Tosari Village. SOCA: Jurnal Sosial Ekonomi Pertanian, 14(3), 511-520. https://doi.org/https://doi.org/10.24843/SOCA.2020.v14.i03.p12 